\title{
SIALIC ACID IN HUMAN SEMEN AND IN THE MALE GENITAL TRACT
}

\author{
BY LEONARD WARREN \\ (From the National Institute of Arthritis and Metabolic Diseases, National Institutes of Health, \\ United States Public Health Service, Bethesda Md.)
}

(Submitted for publication October 28, 1958; accepted January 9, 1959)

There has been in recent years a growing interest in a family of compounds which has the group name sialic acid (1). These aminosaccharides have in common a chain of nine carbon atoms called neuraminic acid (Figure 1). Neuraminic acid itself has not been found naturally, but certain acetyl and glycolyl derivatives have been detected in many of the tissues and fluids of mammals $(2,3)$ and in bacteria (4). Neuraminic acid may bear one acetyl ( $\mathrm{N}$-acetylneuraminic acid) or one glycolyl group (N-glycolylneuraminic acid) on the amino-nitrogen atom, or it may bear two acetyl groups (N,O-diacetylneuraminic acid). In the latter compound the second acetyl moiety is believed to be in ester linkage with the hydroxyl of carbon number seven of neuraminic acid. The structure of these compounds has been established by various workers and $\mathrm{N}$-acetylneuraminic acid has been synthesized by chemical (5) and enzymatic (6) means. Very little sialic acid is found free in tissues and secretions. Most is bound to the carbohydrate portion of mucoproteins and can

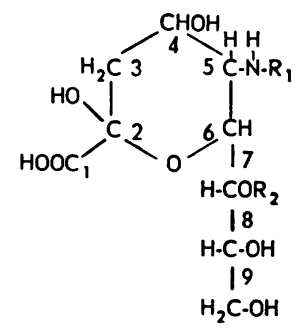

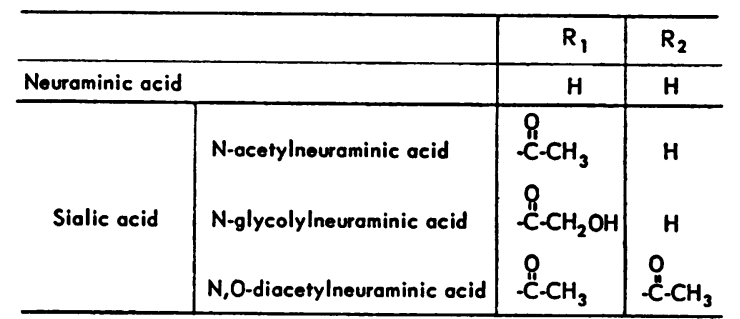

Fig. 1. The Structure of Neuraminic Acid and its Naturally Occurring Derivatives be released by relatively mild acid hydrolysis (2), or by enzmatic action $(7,8)$.

The only data in the literature on seminal sialic acid is a note by Odin (9) on the presence of sialic acid in the gelatinous fragments of hog semen. While our study was in progress, Svennerholm (2) published a new method of analysis for sialic acid in biological materials. The sialic acid content of a number of tissues and secretions was given, among which was an average sialic acid concentration of $105.5 \mathrm{mg}$. per $100 \mathrm{Gm}$. of human semen (four specimens).

As part of a study on the role of sialic acid in fertilization, we have assayed a series of normal and subnormal human semen specimens as well as human prostatic and seminal vesicle secretions and spermatozoa for their content of sialic acid. A study has been made of the sialic acid concentration in semen determined by colorimetric methods directly on semen, and by Svennerholm's method which entails partial purification of sialic acid by an anion exchange column.

\section{MATERIALS}

Semen samples were obtained from individuals who were being investigated for possible infertility. 1 Semen analysis was part of a general examination to investigate the cause of a barren marriage. In most cases colorimetric analysis for sialic acid was carried out within eight hours of ejaculation. There was no decrease in the sialic acid content of semen when it was kept at $2^{\circ} \mathrm{C}$. for two weeks. Semen for other studies was stored at $-15^{\circ} \mathrm{C}$.

Human seminal vesicle and its secretion, prostate and testes were obtained from autopsies carried out in the Pathologic Anatomy Branch of the National Cancer Institute. Normal prostatic secretions were obtained from out-patients at the Urology Clinic of the United States

1 We wish to thank Dr. M. E. Voss of the Oscar B. Hunter Laboratory and Drs. E. E. Ferguson and F. T. Reuter of Washington, D. C. for obtaining this material for us and for carrying out the sperm count and microscopic examination. 
Naval Hospital, Bethesda, Maryland. ${ }^{2}$ Samples were cooled to $0^{\circ} \mathrm{C}$. immediately and analyzed within 1.5 hours.

N-Acetylneuraminic acid was chemically synthesized by the method of Cornforth, Firth and Gottschalk (5). Sialic acid, presumably N,O-diacetylneuraminic acid, was isolated from bovine submaxillary gland mucin, by the method of Blix, Lindberg, Odin and Werner (10).

\section{METHODS}

Ehrlich reaction. All samples of semen were routinely assayed for sialic acid by the direct Ehrlich method of Werner and Odin (11). The assay was modified by reducing the sample size and reagent volume to one-tenth that used by Werner and Odin. Semen was vigorously shaken to attain homogeneity and $0.1 \mathrm{ml}$. diluted to $1 \mathrm{ml}$. with distilled water. Aliquots $(0.1 \mathrm{ml}$. and $0.2 \mathrm{ml}$.) of diluted semen were transferred to test tubes $(10 \times 125$ $\mathrm{mm}$.) and the volume was adjusted to $1 \mathrm{ml}$. with distilled water. A blank consisted of $1 \mathrm{ml}$. distilled water. Ehrlich's reagent $(0.2 \mathrm{ml}$.) was then added (11), the tubes were shaken, capped with glass marbles and placed in a vigorously boiling water bath for exactly $30 \mathrm{~min}-$ utes. The tubes were cooled in water at room temperature for seven minutes and then centrifuged for four minutes in a clinical centrifuge. The clear solutions were pipetted into micro-cuvettes $3 \mathrm{~mm}$. wide, with a light path of $1 \mathrm{~cm}$., and optical densities were determined at $565 \mathrm{~m} \mu$, in a Beckman DU spectrophotometer, equipped with a micro-attachment. Optical density readings were made against the blank.

Two concentrations of semen were used in each assay to ensure that there was no deviation from linearity at the sialic acid levels used. The optical density value produced by $0.2 \mathrm{ml}$. of the diluted semen $(0.02 \mathrm{ml}$. of the original semen sample) was used to calculate the sialic acid concentration. In order to obtain sialic acid concentrations in mg. per $100 \mathrm{ml}$. semen, the observed optical density at $565 \mathrm{~m} \mu$ was multiplied by a factor of $1 ; 130$. A molar extinction coefficient of $1.640 \times 10^{3}$ was used. The sialic acid present is most probably $\mathrm{N}$-acetylneuraminic acid with a molecular weight of 309 . Variation of \pm 3 per cent from the average was observed in six analyses of one semen specimen over the course of a month.

Sialic acid was also assayed by the orcinol method of Werner and Odin (11), by the resorcinol method of Svennerholm (12), and by the diphenylamine procedure of Pigman, Hawkins, Blair and Holley (13).

Anion exchange resin method. A few small modifications of Svennerholm's method were made (2). Onetenth of a ml. of semen was hydrolyzed at $80^{\circ} \mathrm{C}$. in $0.1 \mathrm{~N}$ sulfuric acid for one hour. The samples were cooled and placed on columns of Dowex-1-acetate $(5 \times 0.8 \mathrm{~cm}$.) (X-8, 100-200 mesh). The hydrolysis tubes and columns were washed twice with $5 \mathrm{ml}$. of water and the sialic acid was then eluted into a $10 \mathrm{ml}$. graduated cylinder with 9

2 We wish to thank Capt. J. S. Hanten, M. C., U.S.N., Department of Urology, for obtaining this material. $\mathrm{ml}$. of $1 \mathrm{M}$ sodium acetate buffer, $\mathrm{pH}$ 4.6. Water was added to the graduated cylinders to the $10 \mathrm{ml}$. mark. To 0.2 and $1.0 \mathrm{ml}$. of eluate in $10 \times 125 \mathrm{~mm}$. test tubes, water was added to a volume of $1 \mathrm{ml}$. The blank consisted of $1 \mathrm{ml} .1 \mathrm{M}$ acetate buffer, $\mathrm{pH}$ 4.6. One $\mathrm{ml}$. of resorcinol reagent was added, a bead was placed on top of the tube and the tubes were shaken and then heated in a vigorously boiling water bath for exactly $15 \mathrm{~min}$ utes. The tubes were cooled in running water for 10 minutes and $1.0 \mathrm{ml}$. of isoamyl alcohol was added to each tube. The tubes were shaken vigorously for 20 seconds and centrifuged for 5 minutes in a clinical centrifuge. The clear top phase of isoamyl alcohol was pipetted into cuvettes, $3 \mathrm{~mm}$. wide with a $1 \mathrm{~cm}$. light bath. The optical density at $580 \mathrm{~m} \mu$ was observed in the Beckman DU spectrophotometer equipped with a micro-attachment. In this assay $1 \mu \mathrm{M}$ of $\mathrm{N}$-acetylneuraminic acid in a volume of $1 \mathrm{ml}$. gave an optical density reading at $580 \mathrm{~m} \mu$ of 4.650. Repeated analyses of semen samples agreed within 2 per cent

Control assays were run with 0.2 and $0.3 \mu \mathrm{M}$ of $\mathrm{N}$-acetylneuraminic acid. This is approximately the amount in the semen specimens assayed. A recovery of 91.5 to 94 per cent was observed and the average loss of $\mathrm{N}$-acetylneuraminic acid in seven assays was 7.3 per cent, which is comparable to the figures of Svennerholm (2). We have, therefore, increased our observed sialic acid values by 7.3 per cent to compensate for sialic acid which is either destroyed by acid hydrolysis or is lost on the column.

Experiments have shown that after acid hydrolysis of semen the precipitate formed contains no sialic acid. All of the sialic acid is rendered free and dialyzable. After elution of sialic acid from the column with $9 \mathrm{ml}$. of $1 \mathrm{M}$ acetate buffer no further sialic acid could be eluted, even with $3 \mathrm{~N} \mathrm{HCl}$.

Isolation of sialic acid. Sialic acid was isolated from 3 $\mathrm{Gm}$. each of seminal vesicle, prostate, and testis by heating homogenates of these tissues in $15 \mathrm{ml} .0 .05 \mathrm{~N}$ sulfuric acid for two hours at $80^{\circ} \mathrm{C}$. Sialic acid was also isolated from $10 \mathrm{ml}$. semen by adjusting the $\mathrm{pH}$ to 1.0 with sulfuric acid, and then heating in the above manner. The suspensions were centrifuged at $12,000 \times \mathrm{G}$ for $20 \mathrm{~min}$ utes and the supernatant solutions adjusted to $\mathrm{pH} 8.0$ with a 1 molar solution of $\mathrm{NaOH}$. The solutions were placed on a Dowex-1-formate column (X-8, 100-200 mesh) $(10 \times 0.8 \mathrm{~cm}$. $)$ and washed with $50 \mathrm{ml}$. distilled water, $30 \mathrm{ml} .0 .05 \mathrm{M}$ formic acid, and then eluted with 15 ml. $0.3 \mathrm{M}$ formic acid.

The eluates containing sialic acid were then placed on columns of Norit A-Hyflo Super-cel (Johns Manville), $1: 4(6 \times 0.8 \mathrm{~cm}$. $)$. These were washed with $30 \mathrm{ml}$. of water and the sialic acid was eluted with $20 \mathrm{ml}$. of 40 per cent aqueous methanol. The methanol eluates were evaporated to dryness in vacuo. The material obtained was used for paper chromatography experiments and chemical tests.

Paper chromatography. The descending method was used with Whatman No. 1 paper at room temperature 
for 18 hours. The solvent systems were: 1) $n$-butanol: acetic acid: water $(4: 1: 5) ; 2)$ sec-butanol: acetic acid: water $(4: 1: 5)$; 3) ethyl acetate: pyridine: water (1: $1: 2)$; 4) n-butanol: n-propanol: $0.1 \mathrm{~N} \mathrm{HCl},(1: 2: 1)$ $(10,14)$. To locate the sialic acid, the entire paper strip was cut into sections $1 \mathrm{~cm} . \times 2 \mathrm{~cm}$. wide and placed in 15 $\times 125 \mathrm{~mm}$. test tubes which contained $1 \mathrm{ml}$. distilled water and $0.2 \mathrm{ml}$. Ehrlich's reagent. The usual assay for sialic acid was carried out.

Neuraminidase and semen. The following experiment was performed to see whether the enzyme neuraminidase could cleave sialic acid from seminal mucoprotein, as it does from certain human plasma proteins (8).

One-tenth of a ml. of semen was incubated with 10 $\mu \mathrm{g}$. of neuraminidase and $50 \mu \mathrm{M}$ of sodium acetate buffer, $\mathrm{pH} 5.25$, in a final volume of $0.75 \mathrm{ml}$. After 24 hours, $0.75 \mathrm{ml}$. of 5 per cent phosphotungstic acid in $2 \mathrm{~N} \mathrm{HCl}$ was added to the vessels to precipitate the mucoprotein and the vessels were centrifuged. In this experiment, free, nonprecipitable sialic acid, released by the enzyme, was assayed by the orcinol reaction. This assay was carried out on $1 \mathrm{ml}$. of clear supernatant solution. In the control vessel, enzyme was omitted and no orcinol reacting material was released.

The neuraminidase used was derived from the culture filtrate of Clostridium perfringens (8) and purified 12fold by adsorption and elution from calcium phosphate gel (15).

\section{RESULTS AND DISCUSSION}

Sialic acid levels in normal and subnormal semen

The sialic acid concentrations of 20 normal and 15 subnormal semen specimens were determined (Tables I and II). For this study the decision to place specimens into the normal and subnormal categories was based on laboratory investigation of the semen. Semen which contained less than $60,000,000$ spermatozoa per ml. was considered subnormal $(16,17)$. Specimens with more than $60,000,000$ spermatozoa per $\mathrm{ml}$. with normal motility and sperm morphology were placed in the normal class.

The average number of spermatozoa was 139.7 million per $\mathrm{ml}$. in normal and 19.3 million per $\mathrm{ml}$. in the subnormal specimens. The mean volume of normal ejaculates was $3.6 \mathrm{ml}$., and $3.4 \mathrm{ml}$. in the subnormal. In two other studies the average ejaculate volumes of men from sterile marriages were 3.4 and $3.59 \mathrm{ml} .(16,18)$.

As seen in Table I the average sialic acid concentration of 20 normal semen specimens by the column method was $124.2 \mathrm{mg}$. per cent (standard error of mean, 8.7), with values ranging from 64.5 to $219.0 \mathrm{mg}$. per cent. Subnormal samples
TABLE I

Sialic acid concentration in normal semen

\begin{tabular}{cccc}
\hline \hline Sample & Volume & Spermatozoa & $\begin{array}{c}\text { Sialic } \\
\text { acid }\end{array}$ \\
\hline no. & $m l$. & $n o . / m l . \times 10^{8}$ & $m$ g./100 ml.* \\
1 & 3.5 & 220 & 107.3 \\
2 & 2.8 & 80 & 185.6 \\
3 & 3.2 & 100 & 144.0 \\
4 & 1.5 & 90 & 112.2 \\
5 & 4.3 & 102 & 123.7 \\
6 & 1.5 & 250 & 130.0 \\
7 & 6.0 & 300 & 90.8 \\
8 & 4.0 & 265 & 90.2 \\
9 & 3.0 & 90 & 64.5 \\
10 & 3.5 & 80 & 127.2 \\
11 & 3.0 & 90 & 219.0 \\
12 & 2.1 & 107 & 89.2 \\
13 & 3.8 & 162 & 86.5 \\
14 & 5.6 & 118 & 195.5 \\
15 & 3.6 & 196 & 116.0 \\
16 & 4.6 & 68 & 102.0 \\
17 & 3.6 & 100 & 95.0 \\
18 & 7.4 & 112 & 85.9 \\
19 & 1.6 & 177 & 155.8 \\
20 & 3.9 & 86 & 163.2 \\
& 3.6 & 139.7 & 124.2 \\
Mean & & & 8.7 \\
Standard error of & & & \\
mean & & & \\
\hline
\end{tabular}

* To convert into millimole per liter, divide by 30.9 .

ranged from 42.4 to $134.9 \mathrm{mg}$. per cent with a mean of $90.1 \mathrm{mg}$. per cent (standard error of mean, 6.2), 27.5 per cent lower than the normal (Table II). The difference between the levels of sialic acid in normal and subnormal semen specimens is small but is statistically significant $(p<$ 0.01 ). Svennerholm reported an average of 105.5

TABLE II

Sialic acid concentration in subnormal semen

\begin{tabular}{cccc}
\hline \hline Sample & Volume & Spermatozoa & $\begin{array}{c}\text { Sialic } \\
\text { acid }\end{array}$ \\
\hline no. & $m l$. & $n o . / m l . \times 10^{8}$ & $m g . / 100 \mathrm{ml}$. \\
1 & 1.0 & 8 & 103.8 \\
2 & 3.0 & 20 & 104.2 \\
3 & 4.0 & 15 & 103.8 \\
4 & 1.0 & 1 & 62.8 \\
5 & 2.2 & 27 & 42.4 \\
6 & 2.3 & 0 & 134.9 \\
7 & 2.0 & 7 & 63.9 \\
8 & 4.8 & 14 & 101.5 \\
9 & 3.8 & 35 & 109.7 \\
10 & 3.6 & 5 & 94.0 \\
11 & 7.2 & 11 & 117.7 \\
12 & 3.0 & 38 & 75.7 \\
13 & 4.4 & 43 & 61.2 \\
14 & 3.4 & 29 & 80.5 \\
15 & 5.4 & 37 & 95.6 \\
Mean & 3.4 & 19.3 & 90.1 \\
Standard error of & & & \\
mean & & & 6.2 \\
& & &
\end{tabular}


mg. sialic acid per $100 \mathrm{Gm}$. of semen in four samples (2). The average amount of sialic acid in normal ejaculates was $4.39 \mathrm{mg}$. while in subnormal ejaculates it was $3.11 \mathrm{mg} ., 29.2$ per cent less.

The sialic acid values listed above were obtained by the column method of Svennerholm. In Table III a comparison is made of sialic acid values obtained by the column assay and the Ehrlich assay carried out directly on semen. The Ehrlich assay values were higher due to a material in semen which was not sialic acid but which reacted with the Ehrlich reagent. This material was not adsorbed by the Dowex-1-acetate column and reacted only slightly in the orcinol and resorcinol tests. The differences between the results of the column and Ehrlich method were not constant from specimen to specimen. It is evident that the Ehrlich reaction must be used with caution in the assay of sialic acid in semen and probably in other biological materials as well. In this instance, a significant difference between sialic acid levels of normal and subnormal semen samples was masked in the Ehrlich assay.

Other colorimetric methods such as the orcinol, resorcinol, and diphenylamine assays may also be unsuitable for the measurement of sialic acid in tissues and secretions unless they are partially purified. Free sugars and other nonsialic acid materials in semen react in these tests and obscure the characteristic absorption spectra of the sialic acid chromophore. We have found that dialysis of semen results in a 35 to 85 per cent decrease in the peak optical densities in these reactions.

It may be seen from Tables I and II that a high sialic acid value is not necessarily associated with a high sperm count. The highest sialic acid value among the subnormal specimens was found in one which was devoid of spermatozoa. There is a wide variation in the seminal sialic acid concentration, as there is in the sperm count. This variation of sialic acid levels in semen is considerably greater than it is in serum (19) and synovial fluid (13), and may reflect not only the efficiency of synthesis but the frequency of ejaculation. Hotchkiss found in humans that the total sperm content of an ejaculation was 51 per cent less than one 24 hours previous (17). Sialic acid levels may decrease correspondingly. However, this factor has not been investigated.

Two of the major components of semen, pros-
TABLE III

Averages of sialic acid concentrations of semen by two methods

\begin{tabular}{|c|c|c|}
\hline Method & $\begin{array}{c}\text { Normal } \\
\text { (20 samples) }\end{array}$ & $\begin{array}{c}\text { Subnormal } \\
\text { (15 samples) }\end{array}$ \\
\hline \multirow{2}{*}{$\begin{array}{l}\text { 1. Column } \\
\text { 2. Ehrlich reaction } \\
\text { on semen }\end{array}$} & $\begin{array}{c}m g . / 100 m l \\
124.2\end{array}$ & $\begin{array}{c}m g . / 100 \mathrm{ml} \\
90.1\end{array}$ \\
\hline & 184.5 & 188.0 \\
\hline
\end{tabular}

tatic and seminal vesicle secretions, markedly differ in their sialic acid concentrations (vide infra). Perhaps differences of the relative proportion of these secretions in semen in different individuals or in the same individual may be responsible for the wide variation in the sialic acid level.

\section{Sialic acid in human prostatic and seminal vesicle secretions}

The presence of sialic acid in semen raises the question as to its site of synthesis. The bulk of semen comes from the prostate and seminal vesicles. Since the concentrations of sialic acid in prostatic and seminal vesicle fluids were not known, they were examined by the column method for their content of sialic acid.

It may be seen in Table IV that seminal vesicle fluid contains an average of $231.9 \mathrm{mg}$. of sialic acid per $100 \mathrm{ml}$. determined by the column method. To date, this is the highest sialic acid concentration found in any human tissue or fluid. The mean concentration of sialic acid in prostatic fluid is $60.6 \mathrm{mg}$. per cent ( Table V), determined by the column method.

If these values are used it can be calculated that approximately two parts of prostatic fluid must be mixed with one part of seminal vesicle secretion to attain a concentration of $124.2 \mathrm{mg}$. per cent, the

\begin{tabular}{|c|c|}
\hline Sample & $\begin{array}{l}\text { Sialic } \\
\text { acid }\end{array}$ \\
\hline $\begin{array}{c}n o . \\
1 \\
2 \\
3 \\
4\end{array}$ & $\begin{array}{c}m g . / 100 \mathrm{ml} . \\
216.0 \\
230.2 \\
212.0 \\
269.5\end{array}$ \\
\hline Mean & 231.9 \\
\hline
\end{tabular}


TABLE V

Sialic acid concentration on normal human prostatic secretion

\begin{tabular}{cc}
\hline \hline Sample & $\begin{array}{c}\text { Sialic } \\
\text { acid }\end{array}$ \\
\hline no. & $m g . / 100 \mathrm{ml}$. \\
1 & 56.8 \\
2 & 84.9 \\
3 & 39.6 \\
4 & 71.8 \\
5 & 55.1 \\
6 & 36.9 \\
7 & 75.8 \\
8 & 63.0 \\
Mean & 60.6 \\
\hline
\end{tabular}

average concentration in normal semen. In other words, the prostate may supply two-thirds the volume of the ejaculate. In two other studies, prostatic secretion has been estimated to comprise 41 to 63 per cent of semen $(20,21)$. However, Lundquist has reported that human semen consists of 15.4 to 32.5 per cent prostatic fluid, 46.3 to 80.4 per cent seminal vesicle fluid and 1.6 to 12.9 per cent testicular and epididymal secretion (22).

The testes, epididymus and ductus deferens add little to the volume $(22,23)$ and probably very little to the sialic acid content of semen. Although sialic acid has been isolated from testicular homogenates, spermatozoa which have been washed 12 times contain only a small amount of sialic acid (vide infra).

\section{Sialic acid in spermatozoa}

The removal of spermatozoa from semen by centrifugation does not significantly alter the sialic acid content of semen. There remains, however, the possibility that a small amount of sialic acid is present in the spermatozoa.

A pooled sample of normal semen, $10.5 \mathrm{ml}$. in volume, which contained $96.5 \mathrm{mg}$. per cent of sialic acid and $78 \times 10^{8}$ spermatozoa per $\mathrm{ml}$. was centrifuged at $5,000 \times \mathrm{G}$ for 10 minutes. The spermatozoa were washed 12 times at room temperature, twice with distilled water, six times with physiological saline, twice with $0.2 \mathrm{M}$ acetate buffer, $\mathrm{pH}$ 5.0, and twice with $0.1 \mathrm{M}$ potassium phosphate buffer, $\mathrm{pH} .7 .3$. The spermatozoa were hydrolyzed and analyzed by the colmun method. The $1 \mathrm{M}$ acetate eluate was tested by the Ehrlich and resorcinol tests and found to contain 0.054 mg. of sialic acid, or 0.53 per cent of the total sialic acid of the semen sample. Each sperm cell contains $2.1 \times 10^{-10} \mu \mathrm{M}$ of sialic acid.

It is unlikely that the spermatozoa are contaminated by mucoprotein after 12 washes. In three experiments, absorption spectra characteristic of sialic acid have been observed when the direct Ehrlich test was performed on washed spermatozoa. In one experiment it was observed that some of this sialic acid could be solubilized by partially purified neuraminidase. The function of sialic acid in spermatozoa, as in seminal mucoproteins, is unknown. Perhaps, in some manner sialic acid is involved in the union of ovum and spermatozoa as it is with the interaction of virus and red blood cell (7).

\section{Dialyzable sialic acid in semen}

Two $\mathrm{ml}$. of semen was dialyzed against $100 \mathrm{ml}$. of distilled water, for 20 hours at $4^{\circ} \mathrm{C}$. The dialysate was concentrated in vacuo, and then tested for sialic acid by the Ehrlich assay. In five experiments the amount of sialic acid found in the dialysate was $2.6,3.7,6.4,4.0$ and 4.8 per cent of the total seminal sialic acid value. Some of this material had the same $R_{\mathbf{f}}$ as $\mathrm{N}$-acetylneuraminic acid in Solvent 1.

It is not known whether dialysable sialic acid actually exists in a free state, is bound to another sugar moiety, or is cleaved from seminal mucoprotein as the sample ages. This problem is being investigated at the present time.

\section{The action of neuraminidase (sialidase) on semen}

It was found that a maximum of 79 per cent of sialic acid was released from seminal mucoprotein by partially purified neuraminidase. The sialic acid released is probably bound to mucoprotein by the same neuraminidase sensitive linkage that binds sialic acid to orosomucoid (8).

\section{Identification of sialic acid}

Sialic acid was isolated from semen, seminal vesicle, testis and prostate as described in "Methods." These samples and authentic N-acetylneuraminic acid were adsorbed by Norit $\mathrm{A}$ and could be eluted with 50 per cent aqueous methanol. 
TABLE VI

$R_{f}$ values of sialic acid isolated from natural sources

\begin{tabular}{|c|c|c|c|c|c|c|c|}
\hline \multirow[b]{2}{*}{ Solvent } & \multicolumn{4}{|c|}{ Sialic acid isolated from: } & \multirow{2}{*}{$\begin{array}{c}\text { N-Acetyl- } \\
\text { neuraminic } \\
\text { acid }\end{array}$} & \multirow{2}{*}{$\begin{array}{c}\text { N-Glycolyl- } \\
\text { neuraminic } \\
\text { acid }\end{array}$} & \multirow{2}{*}{$\begin{array}{c}\text { N.O-Diacetyl- } \\
\text { neuraminic } \\
\text { acid }\end{array}$} \\
\hline & $\begin{array}{c}\text { Seminal } \\
\text { vesicle }\end{array}$ & Prostate & Testes & Semen & & & \\
\hline $\begin{array}{l}\text { 1. Sec-butanol:acetic acid: } \\
\text { water, } 4: 1: 5\end{array}$ & 0.67 & 0.65 & 0.67 & 0.67 & 0.67 & & 0.67 \\
\hline $\begin{array}{l}\text { 2. } n \text {-Butanol:acetic acid: } \\
\text { water, } 4: 1: 5\end{array}$ & 0.14 & 0.14 & 0.14 & 0.13 & 0.14 & & 0.13 \\
\hline $\begin{array}{l}\text { 3. Ethyl acetate:pyridine: } \\
\text { water, } 1: 1: 2\end{array}$ & 0.69 & 0.70 & 0.70 & 0.68 & 0.70 & & 0.70 \\
\hline $\begin{array}{l}\text { 4. } n \text {-Butanol: } n \text {-propanol: } \\
0.1 N \mathrm{HCl}, 1: 2: 1\end{array}$ & 0.42 & 0.41 & 0.41 & 0.41 & 0.42 & 0.33 & 0.41 \\
\hline
\end{tabular}

All behaved similarly on columns of Dowex-1-formate and Dowex-1-acetate.

The $R_{f}$ values of the materials from all four sources were the same as those of $\mathrm{N}$-acetyl and $\mathrm{N}, \mathrm{O}$-diacetylneuraminic acid in four solvents (Table VI). In Solvent 4, the $R_{f}$ of the isolated sialic acid differed from that of $\mathrm{N}$-glycolylneuraminic acid (14). However $\mathrm{N}$-acetylneuraminic acid and N,O-diacetylneuraminic acid have the same $R_{f}$ values in all of the solvents used, and so it is not known from this data which of these forms is present.

To differentiate between $\mathrm{N}$-acetyl and N,Odiacetylneuraminic acids, sialic acid was isolated from dialyzed human semen by a method which is used for the isolation of N,O-diacetylneuraminic acid from bovine submaxillary gland mucin (10). The seminal sialic acid was kept at $4^{\circ} \mathrm{C}$. in 0.01 $\mathrm{N} \mathrm{H}_{2} \mathrm{SO}_{4}$ for 18 hours, a process which is known to remove only the O-acetyl group from N,Odiacetylneuraminic acid (10). The solution was neutralized and enzymatically assayed for free acetate (24). ${ }^{8}$

In contrast to the sialic acid of bovine submaxillary gland mucin, no free acetate was detectable in the preparations of sialic acid from semen. This indicates that $\mathrm{N}$-acetylneuraminic acid is the form that is present in human semen.

A solution of sialic acid, which was derived from semen, contained $0.23 \mathrm{mg}$. of sialic acid per $\mathrm{ml}$. by the Ehrlich assay, $0.22 \mathrm{mg}$. per $\mathrm{ml}$. by the orcinol, and $0.23 \mathrm{mg}$. per $\mathrm{ml}$. by the resorcinol test. In each case $\mathrm{N}$-acetylneuraminic acid served as the standard.

\footnotetext{
${ }^{8}$ Acetokinase was kindly supplied by Mr. W. E. Pricer,
}

\section{SUMMARY}

1. The average concentration of sialic acid in 20 normal human semen samples, by the anion exchange column method of Svennerholm, was found to be $124.2 \mathrm{mg}$. per $100 \mathrm{ml}$. with a range of 64.5 to $219.0 \mathrm{mg}$. per $100 \mathrm{ml}$. and a standard error of the mean of 8.7. The average concentration found in 15 human semen samples with a low content of spermatozoa was $90.1 \mathrm{mg}$. per cent with a standard error of the mean of 6.2 and a range of 42.4 to $134.9 \mathrm{mg}$. per cent. The difference between the sialic acid levels in normal and subnormal semen is small but statistically significant $(p<0.01)$. A small amount of the seminal sialic acid was found to be dialyzable. Partially purified neuraminidase removed a maximum of 79 per cent of the sialic acid from seminal mucoprotein.

2. The average sialic acid concentration of eight samples of human prostatic fluid was $60.6 \mathrm{mg}$. per cent. Four samples of human seminal vesicle secretion had an average sialic acid concentration of $231.4 \mathrm{mg}$. per cent. This is the highest concentration reported in any human tissue or secretion. It has been estimated from these values that the prostate accounts for approximately two-thirds the volume of semen while the seminal vesicles provide one-third.

3. In one experiment it was found that human spermatozoa contained 0.53 per cent of the total seminal sialic acid content.

4. Sialic acid, isolated from human semen, seminal vesicle, testis and prostate, has been compared to $\mathrm{N}$-acetyl, N,O-diacetyl and N-glycolylneuraminic acid. N-Acetylneuraminic acid is the form of sialic acid found in human semen. 
5. The column assay of Svennerholm, and the Ehrlich assay, are compared. The unreliability of colorimetric assays for sialic acid directly on semen is discussed.

\section{ACKNOWLEDGMENTS}

The author wishes to thank Mrs. M. L. Smith for technical assistance.

\section{REFERENCES}

1. Blix, F. G., Gottschalk, A., and Klenk, E. Proposed nomenclature in the field of neuraminic and sialic acids. Nature (Lond.) 1957, 179, 1088.

2. Svennerholm, L. Quantitative estimation of sialic acids. III. An anion exchange resin method. Acta chem. scand. 1958, 12, 547.

3. Chatagnon, C., and Chatagnon, P. L'acide neuraminique. Constituant naturel des tissus et des liquides biologiques de l'homme et des animaux; son interêt en biologie médicale. Presse méd. 1955, 63, 1194.

4. Barry, G. T. Colominic acid, a polymer of N-acetylneuraminic acid. J. exp. Med. 1958, 107, 507.

5. Cornforth, J. W., Firth, M. E., and Gottschalk, A. The synthesis of $\mathrm{N}$-acetylneuraminic acid. Biochem. J. 1958, 68, 57.

6. Comb, D. G., and Roseman, S. Composition and enzymatic synthesis of $\mathrm{N}$-acetylneuraminic acid (sialic acid). J. Amer. chem. Soc. 1958, 80, 497.

7. Gottschalk, A. Virus enzymes and virus templates. Physiol. Rev. 1957, 37, 66.

8. Popenoe, E. A., and Drew, R. M. The action of an enzyme of Clostridium perfringens on orosomucoid. J. biol. Chem. 1957, 228, 673.

9. Odin, L. Sialic acid in human cervical mucus, in hog seminal gel, and in ovomucin. Acta chem. scand. 1955, 9, 1235.

10. Blix, G., Lindberg, E., Odin, L., and Werner, I. Studies on sialic acids. Acta Soc. Med. upsalien. 1956, 61, 1.

11. Werner, I., and Odin, L. On the presence of sialic acid in certain glycoproteins and in gangliosides. Acta Soc. Med. upsalien. 1952, 57, 230.

12. Svennerholm, L. Quantitative estimation of sialic acids. II. A colorimetric resorcinol-hydrochloric acid method. Biochim. biophys. Acta 1957, 24, 604.

13. Pigman, W., Hawkins, W. L., Blair, M. G., and Holley, H. L. Sialic acid in normal and arthritic human synovial fluids. Arth. and Rheum. 1958, 1, 151.

14. Svennerholm, E., and Svennerholm, L. Quantitative paper partition chromatography of sialic acids. Nature (Lond.) 1958, 181, 1154.

15. Warren, L. Unpublished data.

16. Johansson, C.-J. Clinical studies on sterile couples with special reference to the diagnosis, etiology and prognosis of infertility. Acta obstet. gynec. scand. 1957, 36, Suppl. 5.

17. Hotchkiss, R. S. Fertility in Men. Philadelphia, J. B. Lippincott Company, 1944.

18. MacLeod, J. The male factor in fertility and infertility. An analysis of ejaculate volume in 800 fertile men and in 600 men in infertile marriage. Fertil. and Steril. 1950, 1, 347.

19. Saifer, A., and Gerstenfeld, S. The serum neuraminic acid distribution. I. Methodology. J. Lab. clin. Med. 1957, 50, 17.

20. Gutman, A. B., and Gutman, E. B. Quantitative relations of a prostatic component ("acid" phosphatase) of human seminal fluid. Endocrinology 1941, 28, 115.

21. Hansen, P. F. Determination of the "acid" prostatic phosphatase as a new method for medicolegal demonstration of sperm spots. Acta path. microbiol. scand. 1946, 23, 187.

22. Lundquist, F. Aspects of the biochemistry of human semen. Acta physiol. scand. 1949, 19, Suppl. 66.

23. Mann, T. The Biochemistry of Semen. London, Methuen and Company, Ltd., 1954.

24. Rose, I. A. Acetate kinase of bacteria (acetokinase) in Methods in Enzymology, S. P. Colowick and N. O. Kaplan, Eds. Academic Press Inc., New York, 1955, vol. I, p. 591. 